\title{
Design and simulation of dual-band rectangular microstrip patch array antenna for millimeter-wave
}

\author{
Shahad Dhari Sateaa, Maysam Sameer Hussein, Zainab Ghazi Faisal, Amany Mohammad Abood, \\ Huda Dhari Satea \\ Department of Computer Techniques Engineering, Al Esraa University College, Baghdad, Iraq
}

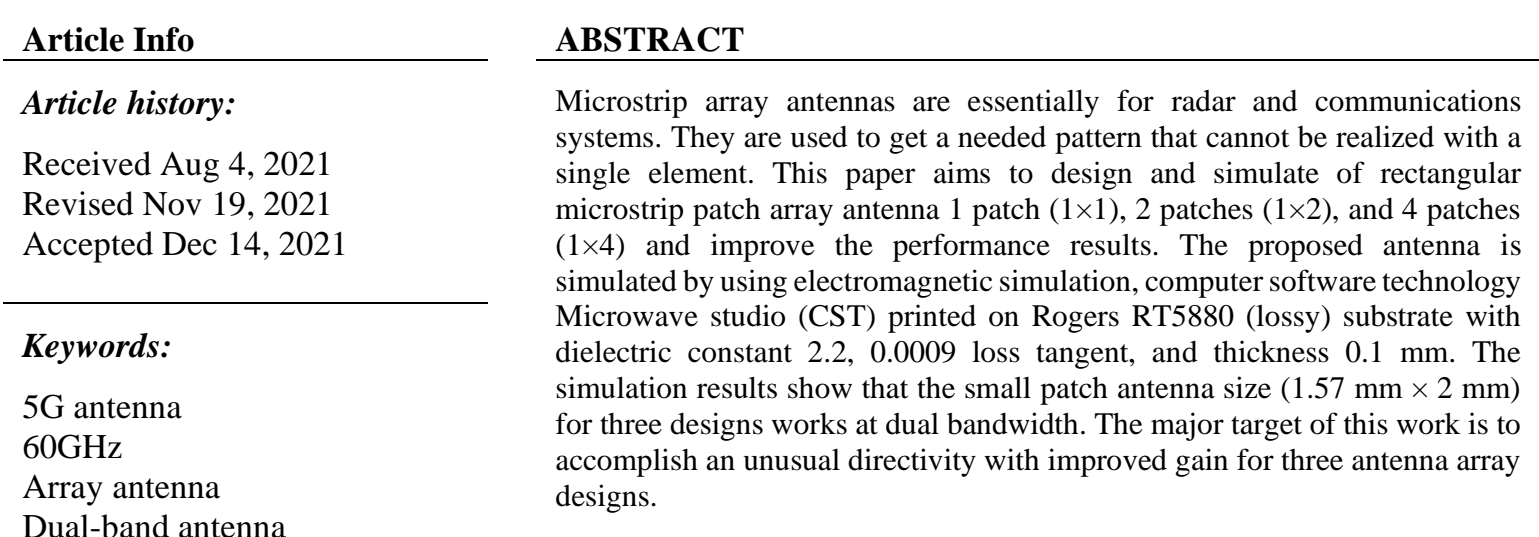

This is an open access article under the CC BY-SA license.

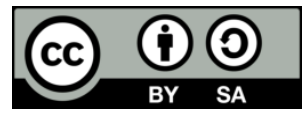

\section{Corresponding Author:}

Shahad Dhari Sateaa

Department of Computer Techniques Engineering, Al-Esraa University College

Baghdad Karrrad/Andalus Square, Iraq

Email: shahad@esraa.edu.iq

\section{INTRODUCTION}

With the rapid improvement in radio telecommunication and wireless systems, antenna design has always been a challenging topic to improve the characteristics of antenna such as size, reflection coefficient, different bandwidths, VSWR, gain, and directivity. This condition leads to several proposals to achieve adjustments between proposal, high gain, antenna dimension, large bandwidth, and low cost [1]-[5]. To fulfill multi-band there are three types of antenna: slot antenna, a monopole antenna, and patch antenna [6]-[15]. The technology of $5 \mathrm{G}$ that holds the millimeter wave is involved to overcome current limits like slow data transmission rate and spectrum shortage. The 5G technology also propositions better analysis as matched to that of earlier generations [16], [17]. Millimeter waves have an unemployed range 3-300 $\mathrm{GHz}$ to satisfy the novel generation's requests. The application of the $5 \mathrm{G}$ range is $(20 \mathrm{GHz}-90 \mathrm{GHz})$ [18].

In various radar and communications systems, microstrip array antennas are deeply favorite. They are used, to produce a required pattern that a single element cannot be realized. The array antenna system is used to augment the directivity, gain and perform different other purposes which would be complex with any single element [19]. D. Imran et al. [20], a simple microstrip patch antenna $(1 \times 1)$ and $(1 \times 4)$ RMSPAA is designed with patch size $(2 \mathrm{~mm} \times 2 \mathrm{~mm})$. Microstrip patch antenna $(1 \times 1)$ gives dual-band at $38 \mathrm{GHz}$ and $54 \mathrm{GHz}$ frequencies and array $(1 \times 4)$ gives $38.6 \mathrm{GHz}, 47.7 \mathrm{GHz}$, and $54 \mathrm{GHz}$ frequencies. Research by Dheyab and Qasem [21] shows three designs $(1 \times 1,1 \times 2$, and $1 \times 4$ RMSPAA) at patch dimension $(1.62 \mathrm{~mm} \times 2 \mathrm{~mm})$. The three array antenna works at frequency $60 \mathrm{GHz}$. $(1 \times 1,1 \times 2$, and $1 \times 4$ RMSPAA) with patch size $(9.31$ $\mathrm{mm} \times 11.86 \mathrm{~mm}$ ) is designed to work at frequency $10 \mathrm{GHz}$ [22]. Research by Prakasam et al. [23], simple 
microstrip patch antenna $(1 \times 2)$ and $(1 \times 4)$ RMSPAA is designed to work at frequency $2.45 \mathrm{GHz}$ with patch dimension $(27.62 \mathrm{~mm} \times 35.79 \mathrm{~mm})$.

In this paper, a tiny and simple structure dual-band microstrip patch array antenna is estimated. Rogers RT5880 (lossy) substrate with dielectric constant 2.2, 0.0009 loss tangent, and thickness $0.1 \mathrm{~mm}$ is used. The patch sizes are $1.57 \mathrm{~mm} \times 2 \mathrm{~mm}$ x $0.035 \mathrm{~mm}$ with a quarter-wave transmission line. This paper proposed an array antenna with good performance, gain, directivity, VSWR, return loss, and bandwidth. The organization of this paper is summarized as; section 2 displays the design and geometry of RMSPAA, section 3, displays simulation results of three arrays and comparison, and in section 4, the results of this research have been discussed.

\section{METHOD OF DESIGN AND GEOMETRY OF RMSPAA}

The constructions and geometry of the single patch $(1 \times 1), 2$ patches $(1 \times 2)$, and 4 patchs $(1 \times 4)$ array antenna are presented.

\subsection{Single element RMSPA}

The process of any MSPA design involves the design of the patch, the feedline, and the matching component. There are three main parameters necessary to design any microstrip antenna: the first one is the dielectric of a substrate $(\varepsilon r)$, the second is the substrate height $(h)$, and the last is the resonant frequency $(f r)$ [24]. Table 1 presentations the necessary factors selected for this project.

Table 1. Parameter values of MSPA

\begin{tabular}{cc}
\hline Parameters & Value \\
\hline Operating frequency $(f r)$ & $60 \mathrm{GHz}$ \\
Constant of substrate dielectric $(\varepsilon r)$ & 2.2 \\
Height of substrate $(\mathrm{h})$ & $0.1 \mathrm{~mm}$ \\
Input impedance $($ Rin $)$ & $50 \Omega$ \\
\hline
\end{tabular}

The dimensions of any design antenna are computed using the distinguished microstrip patch antenna formulas as specified [24], [25]:

$$
W=\frac{c}{2 f_{r}} \sqrt{\frac{2}{\varepsilon_{r}+1}}
$$

where: $\mathrm{W}$ is the width of the patch, $\mathrm{c}$ is $3 \times 10^{8}$, and $\varepsilon r$ is the substrate dielectric constant of Rogers RT5880 with loss tangent 0.0009 .

$$
\varepsilon_{\text {reff }}=\frac{\varepsilon_{r}+1}{2}+\frac{\varepsilon_{r}-1}{2} \frac{1}{\sqrt{1+12 \frac{h}{w}}}
$$

where: $\varepsilon_{\text {reff }}$ is the effective dielectric constant of MSPA.

$$
\Delta L=0.412 h \frac{\left(\varepsilon_{\text {reff }}+0.3\right)\left(\frac{W}{h}+0.264\right)}{\left(\varepsilon_{\text {reff }}-0.258\right)\left(\frac{W}{h}+0.8\right)}
$$

where: $\Delta \mathrm{L}$ is the extension length.

$$
L=\frac{c}{2 f_{r} \sqrt{\varepsilon_{r e f f}}}-2 \Delta L
$$

where $\mathrm{L}$ is the actual length.

$$
W_{S}=W * 2
$$

where: $W_{S}$ is the width of the substrate.

$$
L_{S}=L * 2
$$

where: $L_{S}$ is the length of the substrate.

$$
L_{f}=3.96 * W_{f}
$$


where: $L_{f}$ is the length of the feed line and $W_{f}$ is the width of the feed line

$$
\begin{aligned}
& W_{f}=\frac{2 h}{\pi}\left\{B-1-\ln (2 B-1)+\frac{\varepsilon_{r}-1}{2 \varepsilon_{r}}\left[\ln (B-1)+0.39-\left(\frac{0.61}{\varepsilon_{r}}\right)\right]\right\} \\
& B=\frac{377 \pi}{2 Z_{0} \sqrt{\varepsilon_{r}}}
\end{aligned}
$$

The quarter wave transformer is a microstrip line spent as a proper matching method. The quarter wave transformer is spent among the microstrip line and midpoint along the width of the rectangular patch element for matching their impedances.

$$
L_{T}=\frac{\lambda_{0}}{4 \sqrt{\varepsilon_{R}}}
$$

where: $L_{T}$ is the length of the quarter-wave transformer and $\lambda_{0}$ is the wavelength.

$$
Z_{T}=\sqrt{Z_{0} Z_{P}}
$$

where: $Z_{T}$ is the impedance of the quarter-wave transformer, $Z_{0}$ is the feedline impedance (50 $\Omega$ ), and $Z_{P}$ impedance attainable by the patch at the midpoint along the width of the patch. The input impedance at the midpoint along the width is [24].

$$
Z_{P}=\frac{1}{2 G_{1}}
$$

where

$$
G_{1}= \begin{cases}\frac{1}{90}\left(\frac{W}{\lambda_{0}}\right)^{2} & W \ll \lambda_{0} \\ \frac{1}{120}\left(\frac{W}{\lambda_{0}}\right) & W \gg \lambda_{0}\end{cases}
$$

Table 2 shows the dimensions which were calculated using the equations and optimized for a rectangular MPA. Figure 1 shows a single element RMSPA.

Table 2. Calculated and optimized RMSPA parameters

\begin{tabular}{lcc}
\hline \multicolumn{1}{c}{ Parameter } & Calculated & Optimized \\
\hline Patch width $(\mathrm{W})$ & $1.97 \mathrm{~mm}$ & $2 \mathrm{~mm}$ \\
Patch length $(\mathrm{L})$ & $1.63 \mathrm{~mm}$ & $1.57 \mathrm{~mm}$ \\
Substrate width $\left(W_{S}\right)$ & $3.94 \mathrm{~mm}$ & $2.5 \mathrm{~mm}$ \\
Substrate length $\left(L_{S}\right)$ & $3.26 \mathrm{~mm}$ & $3 \mathrm{~mm}$ \\
Feedline width $\left(W_{f}\right)$ & $0.308 \mathrm{~mm}$ & $0.308 \mathrm{~mm}$ \\
Feedline length $\left(L_{f}\right)$ & $1.21968 \mathrm{~mm}$ & $0.465 \mathrm{~mm}$ \\
Transmission line width $\left(W_{T)}\right.$ & $0.089 \mathrm{~mm}$ & $0.089 \mathrm{~mm}$ \\
Transmission line length $\left(L_{T}\right)$ & $0.843 \mathrm{~mm}$ & $0.84 \mathrm{~mm}$ \\
\hline
\end{tabular}
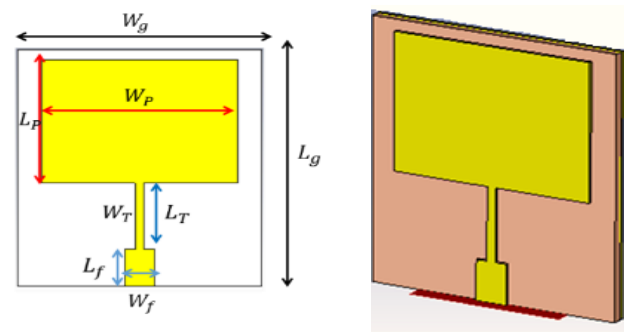

Figure 1. Single element RMSPA

\section{2. $1 \times 2$ and $1 \times 4$ RMSPA antenna design}

Figure 2 shows $1 \times 2$, and $1 \times 4$ RMSPA array. The dimensions used to design the single patch antenna are the same as those used for the array antenna design and the substrate used the same type as mentioned above. The overall sizes of the ground and the substrate are equal to $5 \times 6 \mathrm{~mm}$. The spacing between the rectangular patch array elements is equal to $\lambda_{g} / 2$, where $\lambda_{g}$ is the guided wavelength determined applying the equations offered in [21]. A corporate feeding network is resolved from mathematical equations related in [22]. Three different values of microstrip lines are $50 \Omega, 70.7 \Omega$, and $100 \Omega$ the dimension of each feeding shows in Table 3 .

Table 3. Dimension of the corporate feeding network

\begin{tabular}{cccccccc}
\hline$L_{1}$ & $W_{1}$ & $L_{2}$ & $W_{2}$ & $L_{3}$ & $W_{3}$ & $L_{4}$ & $W_{4}$ \\
\hline $0.089 \mathrm{~mm}$ & $1.047 \mathrm{~mm}$ & $0.46 \mathrm{~mm}$ & $0.176 \mathrm{~mm}$ & $0.465 \mathrm{~mm}$ & $0.308 \mathrm{~mm}$ & $0.47 \mathrm{~mm}$ & $0.089 \mathrm{~mm}$ \\
\hline
\end{tabular}




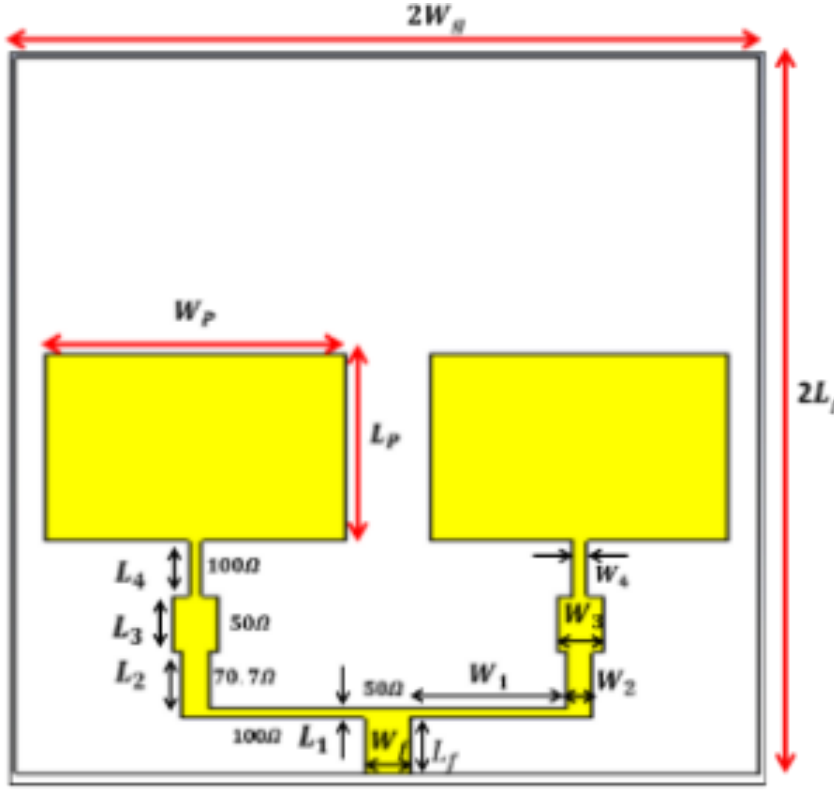

(a)

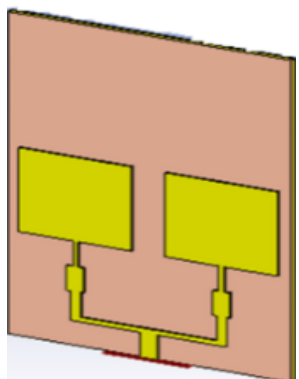

(a)

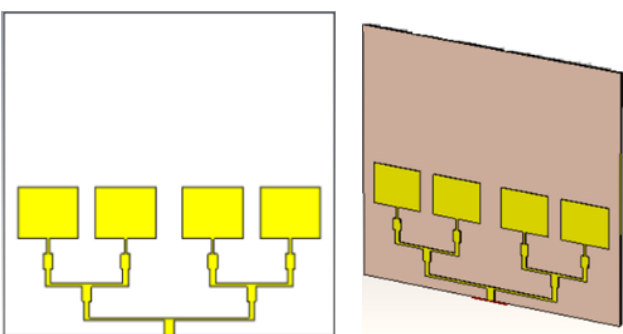

(b)

Figure 2. Design of RMSPA array (a) 1×2 RMSPAA and (b) $1 \times 4$ RMSPAA

\section{SIMULATION RESULTS OF THREE ARRAYS AND ANALYSIS}

In this section, the results and simulation obtained by using the CST STUDIO SUITE Version 2019 will be explained. VSWR, bandwidth, return loss, gain, directivity, and the current surface for each $1 \times 1,1 \times 2$, and $1 \times 4$ element array antenna will be displayed. Theoretically, the return loss amount should be less than $-10 \mathrm{~dB}$, and the VSWR amount varies from 1 to 2 .

\subsection{Result of the single element}

The result of the $1 \times 1$ element appears the design work with dual-band ( $60 \mathrm{GHz}$ with bandwidth $1.2 \mathrm{GHz})$, and $(93.7 \mathrm{GHz}$ with a bandwidth equal to $1.1 \mathrm{GHz})$. Table 4 shows the result of the $1 \times 1$ element at each frequency. Figure 3 shows return loss and VSWR equal 1.475 at $60 \mathrm{GHz}$ and it's equal to 1.6682 at 93.7 GHz. From Figure 4 directivity is equal to $(7.493 \mathrm{dBi}$ at $60 \mathrm{GHz})$ and $(7.376 \mathrm{dBi}$ at $93.7 \mathrm{GHz})$. The gain at frequency $60 \mathrm{GHz}$ is $6.673 \mathrm{dBi}$ and at $93.7 \mathrm{GHz}$ is $6.833 \mathrm{dBi}$ as shown in Figure 5. The maximum surface current for $60 \mathrm{GHz}$ is $844.371 \mathrm{~A} / \mathrm{m}$ and for $93.7 \mathrm{GHz}$ is $669.894 \mathrm{~A} / \mathrm{m}$ as shown in Figure 6.

Table 4. Result of the single element of RMSP array antenna

\begin{tabular}{cccccc}
\hline Frequency $(\mathrm{GHz})$ & Return loss $(\mathrm{dB})$ & VSWR & Bandwidth $(\mathrm{GHz})$ & Directivity $(\mathrm{dBi})$ & Gain $(\mathrm{dBi})$ \\
\hline 60 & -14.338 & 1.475 & 1.2 & 7.493 & 6.673 \\
93.7 & -12.027 & 1.6682 & 1.1 & 7.376 & 6.833 \\
\hline
\end{tabular}

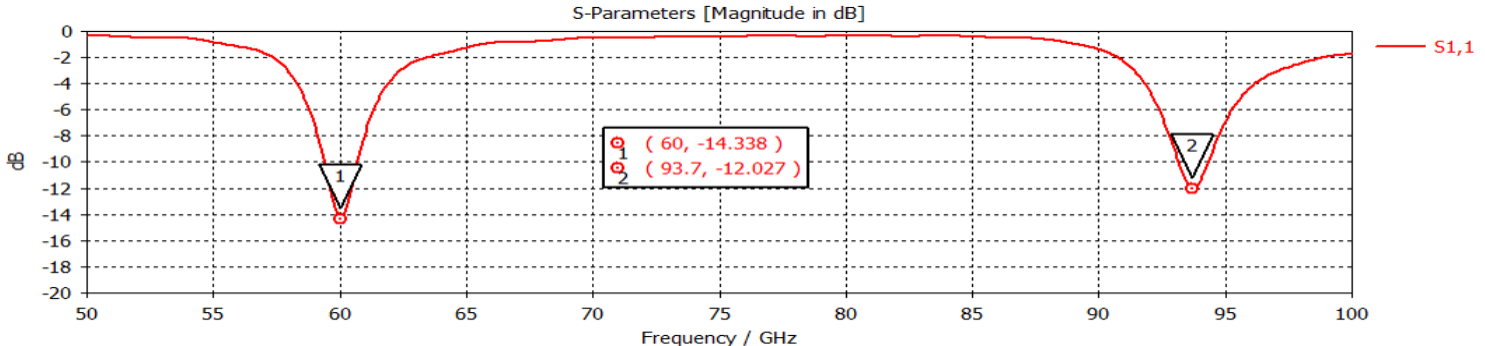

(a)

Figure 3. Dual-band of a single element (a) return loss 


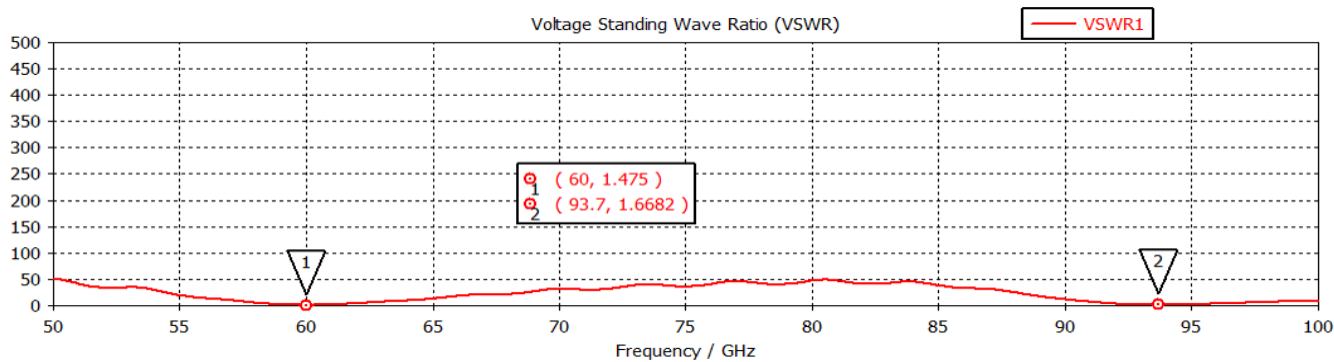

(b)

Figure 3. Dual-band of a single element (b) VSWR (continue)

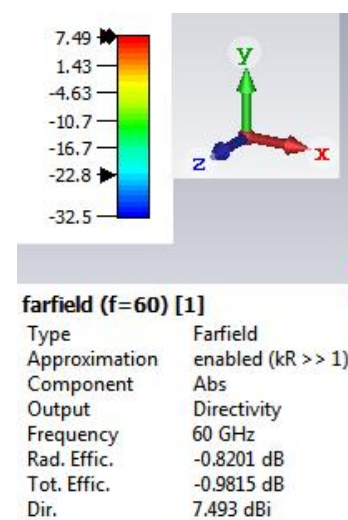

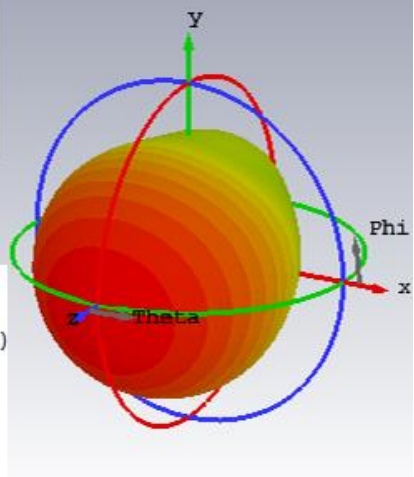

(a)

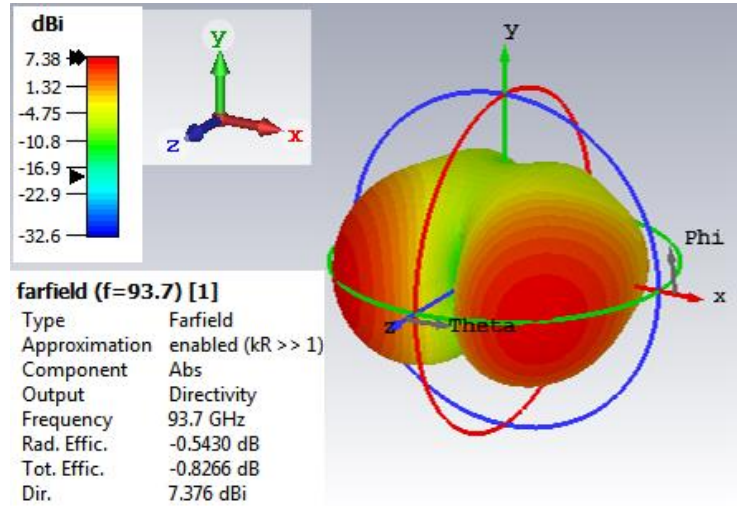

(b)

Figure 4. Directivity of the single element at (a) $60 \mathrm{GHz}$ and (b) $93.7 \mathrm{GHz}$

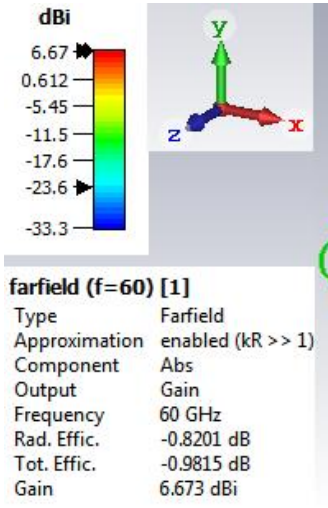

(a)

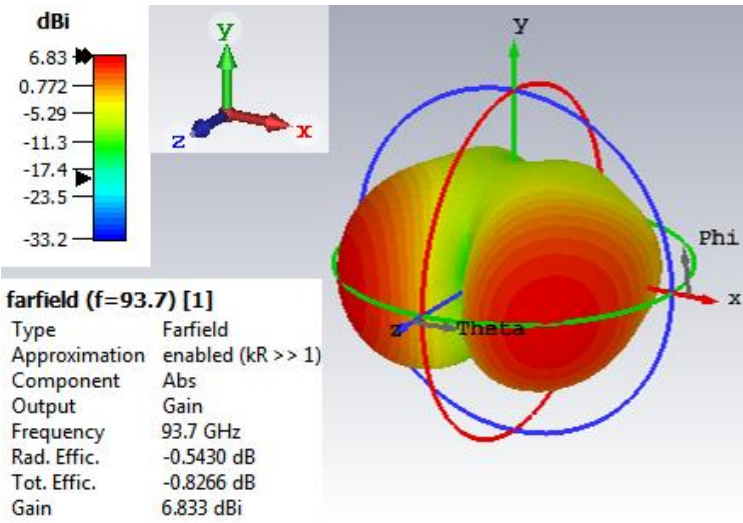

(b)

Figure 5. Gain of the single element at (a) $60 \mathrm{GHz}$ and (b) $93.7 \mathrm{GHz}$

\subsection{Result of the $1 \times 2$ RMSP array antenna}

Design 2 patches $(1 \times 2)$ array element of RMSPA appears its work with dual-band $(60 \mathrm{GHz}$ and $94.4 \mathrm{GHz})$ as displayed in Table 5. The results of the $(1 \times 2)$ array antenna show there is an enhancement compared to the results of the single element at frequency $60 \mathrm{GHz}$. The other frequency shifts up to $94.4 \mathrm{GHz}$ with -19.669 dB return loss, 1.2319 VSWR, and bandwidth equal to1.8 GHz as shown in Figure 7. The results of the directivity appear enhancement at $60 \mathrm{GHz}$ equal to $8.616 \mathrm{dBi}$, and at $94.4 \mathrm{GHz}$ equal to $6.425 \mathrm{dBi}$ as shown in Figure 8. The gain at frequency $60 \mathrm{GHz}$ is $8.125 \mathrm{dBi}$ and at 94.4 is $5.431 \mathrm{dBi}$ as shown in Figure 9. Figure 10 appear that the maximum surface current for $60 \mathrm{GHz}$ is $612.533 \mathrm{~A} / \mathrm{m}$ and for 94.4 is $510.42 \mathrm{~A} / \mathrm{m}$. The results show that the performance of 2 patches $(1 \times 2)$ is best than the performance of 1 patch $(1 \times 1)$. 


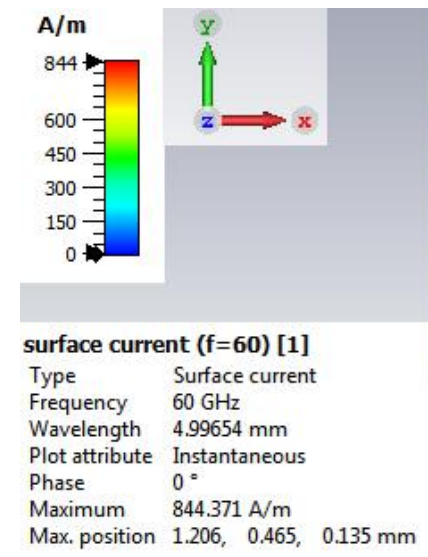

(a)

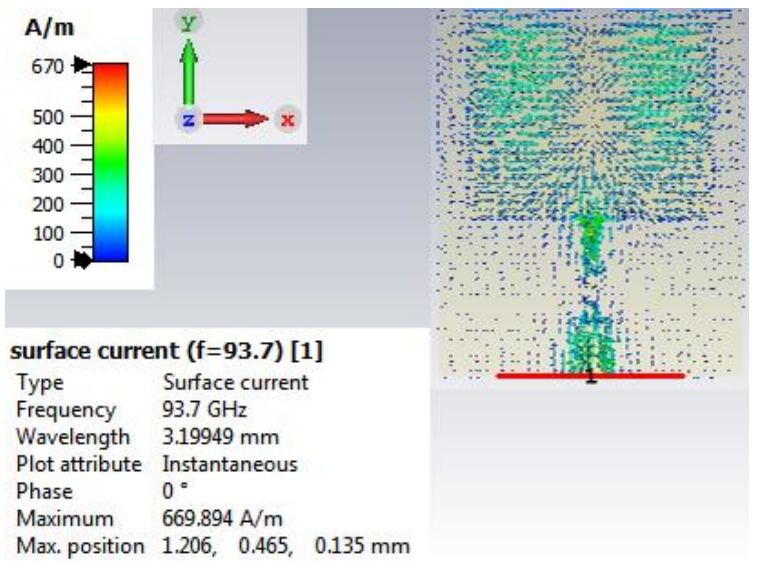

(b)

Figure 6. Current surface of the single element at (a) $60 \mathrm{GHz}$ and (b) $93.7 \mathrm{GHz}$

Table 5. Result of the $(1 \times 2)$ RMSPA antenna

\begin{tabular}{cccccc}
\hline Frequency $(\mathrm{GHz})$ & Return loss & VSWR & Bandwidth $(\mathrm{GHz})$ & Directivity $(\mathrm{dBi})$ & Gain $(\mathrm{dBi})$ \\
\hline 60 & $-43.141(\mathrm{~dB})$ & 1.014 & 1.7 & 8.616 & 8.125 \\
94.4 & $-19.669(\mathrm{~dB})$ & 1.2319 & 1.8 & 6.425 & 5.431 \\
\hline
\end{tabular}

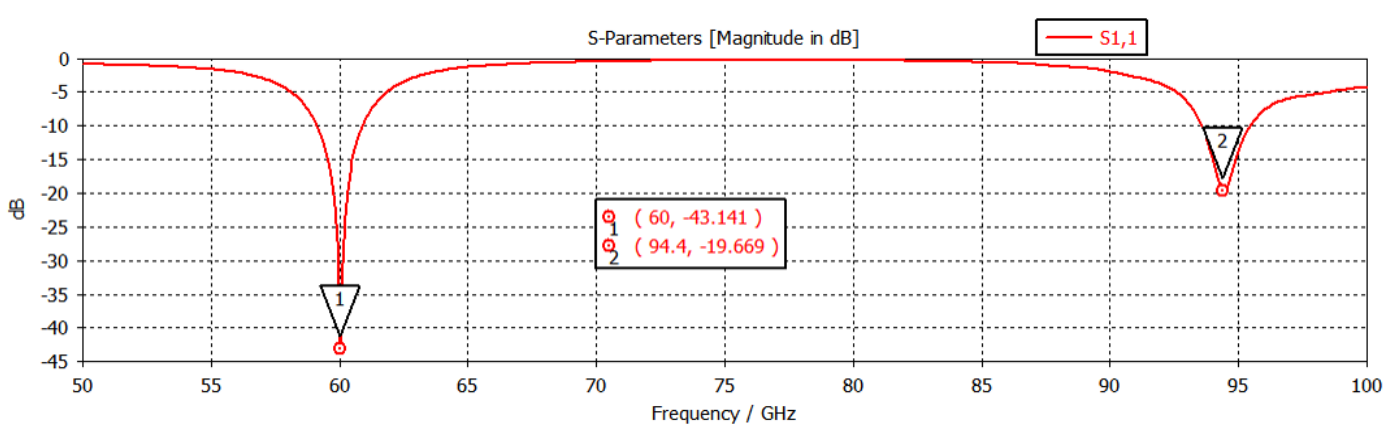

(a)

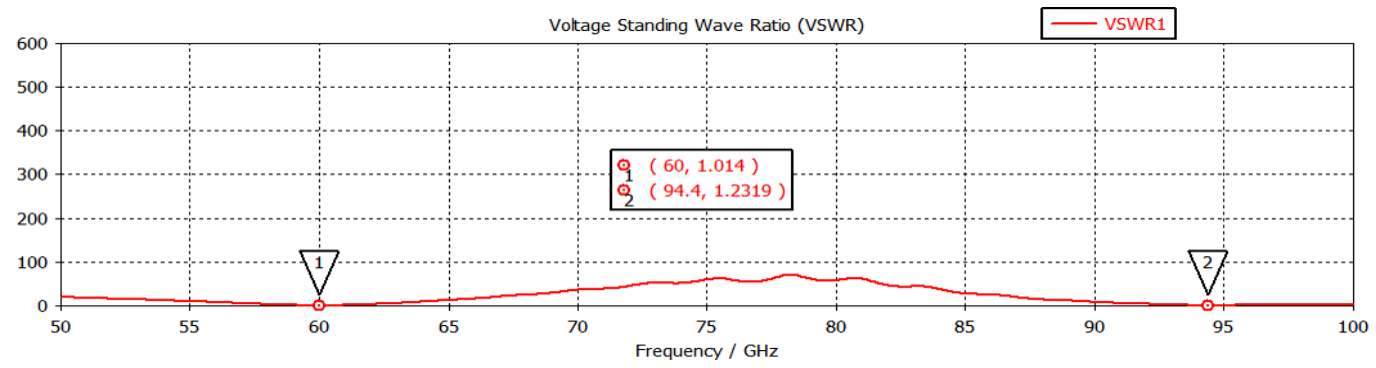

(b)

Figure 7. Dual-band of a 2patches $(1 \times 2)$ array antenna (a) return loss and (b) VSWR

\subsection{Result of the $1 \times 4$ array RMSPA}

Dual bandwidth $(60 \mathrm{GHz}$ and $92.8 \mathrm{GHz})$ operates with a $1 \times 4$ array antenna. Table 6 shows that the frequency $60 \mathrm{GHz}$ works at $1.0879 \mathrm{VSWR},-27.512 \mathrm{~dB}$ return loss, and bandwidth equal to at $1.7 \mathrm{GHz}$ as shown in Figure 11. The gain $(11.01 \mathrm{dBi})$ and directivity $(11.54 \mathrm{dBi})$ of $1 \times 4$ array at $60 \mathrm{GHz}$ show an improvement over comparing with $1 \times 1$, and $1 \times 2$ array. The frequency $(92.2 \mathrm{GHz})$ have directivity equal to $(10.50 \mathrm{dBi})$ and gain equal to $(9.211 \mathrm{dBi})$ as shown in Figure 12 and 13 . According to Figure 14, the maximum surface current for $60 \mathrm{GHz}$ is $546.161 \mathrm{~A} / \mathrm{m}$ and for 94.4 is $5210.973 \mathrm{~A} / \mathrm{m}$. The results show that the performance of 4 patches $(1 \times 4)$ is best than the performance of both 1 patch $(1 \times 1)$ and 2 patches $(1 \times 2)$. 


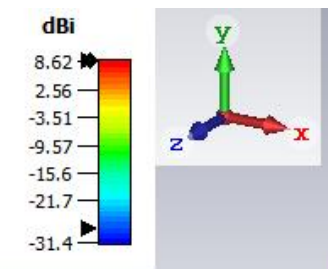

farfield $(f=60)[1]$

Type Farfield

Approximation enabled $(k R>>1)$

Component Abs

$\begin{array}{ll}\text { Component } & \text { Abs } \\ \text { Output } & \text { Directivity }\end{array}$

Frequency

Rad. Effic.
Tot. Effic.

$60 \mathrm{GHz}$

$-0.4913 \mathrm{~dB}$

$-0.4915 \mathrm{~dB}$

$8.616 \mathrm{dBi}$

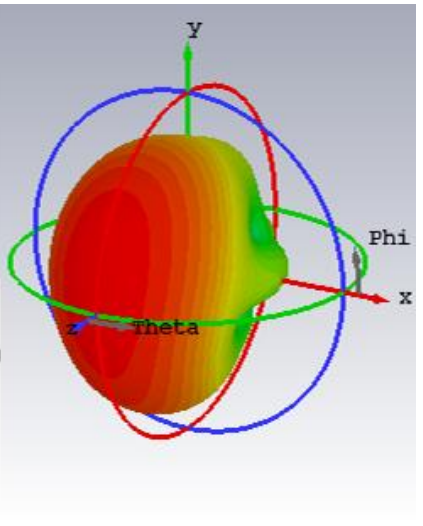

(a

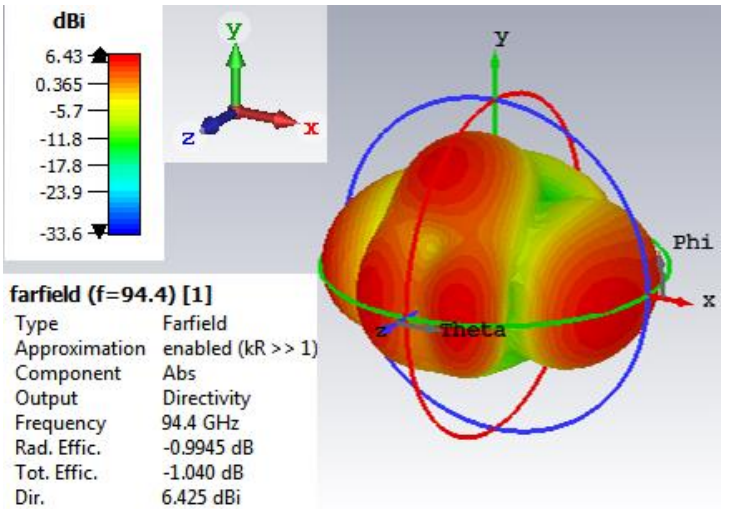

(b)

Figure 8. Directivity of $1 \times 2$ array at (a) $60 \mathrm{GHZ}$ and (b) $94.4 \mathrm{GHz}$

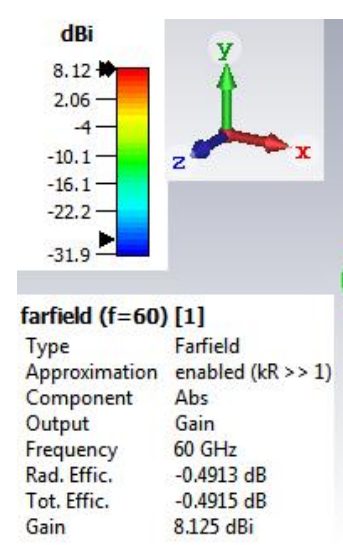

(a)

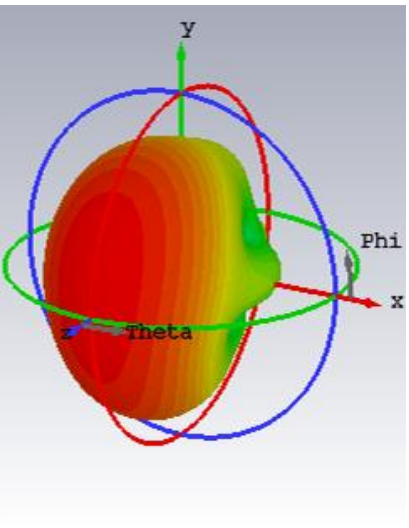

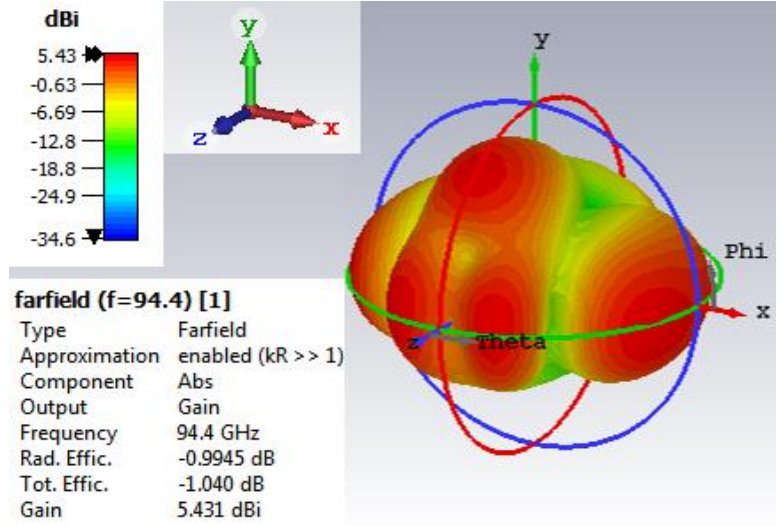

(b)

Figure 9. Gain of $1 \times 2$ array at (a) $60 \mathrm{GHz}$ and (b) $94.4 \mathrm{GHz}$

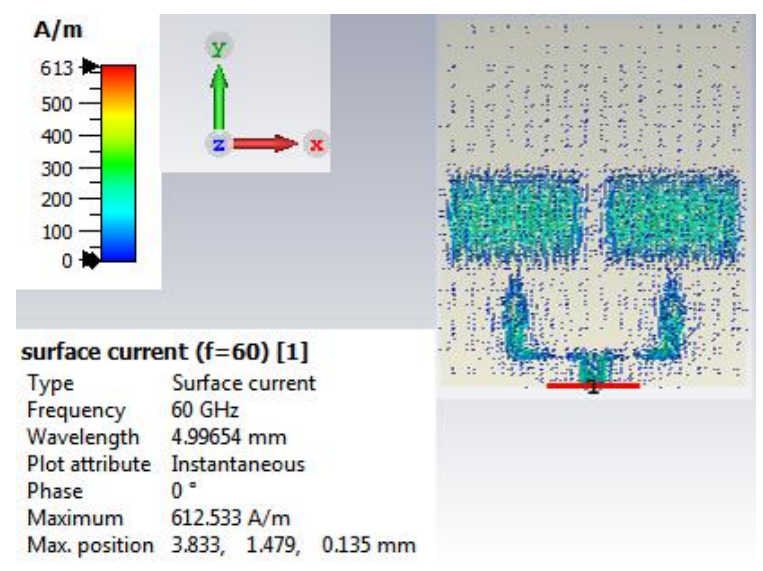

(a)

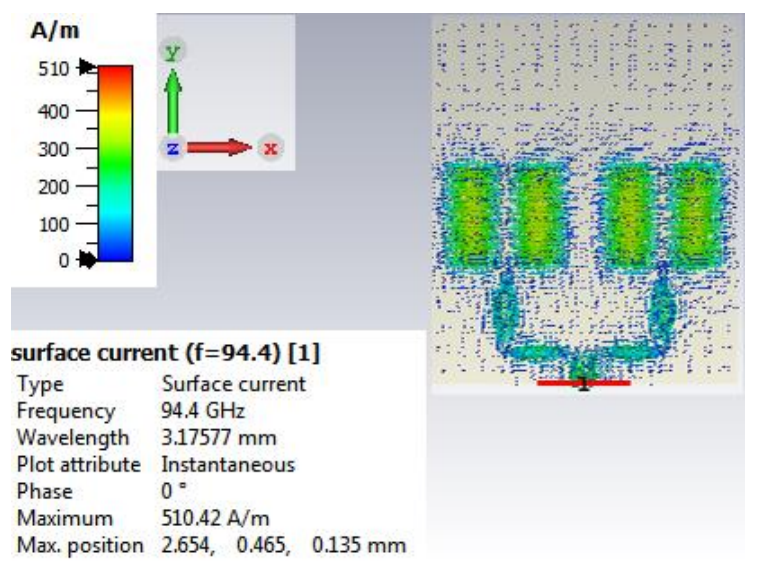

(b)

Figure 10. Current surface of $1 \times 2$ array at (a) $60 \mathrm{GHz}$ and (b) $94.4 \mathrm{GHz}$

Table 6 . Result of the $(1 \times 2)$ RMSPA antenna

\begin{tabular}{cccccc}
\hline Frequency $(\mathrm{GHz})$ & Return loss & VSWR & Bandwidth $(\mathrm{GHz})$ & Directivity $(\mathrm{dBi})$ & Gain $(\mathrm{dBi})$ \\
\hline 60 & $-27.514(\mathrm{~dB})$ & 1.0879 & 1.7 & 11.54 & 11.01 \\
92.8 & $-14.67(\mathrm{~dB})$ & 1.4531 & 0.9 & 10.50 & 9.211 \\
\hline
\end{tabular}




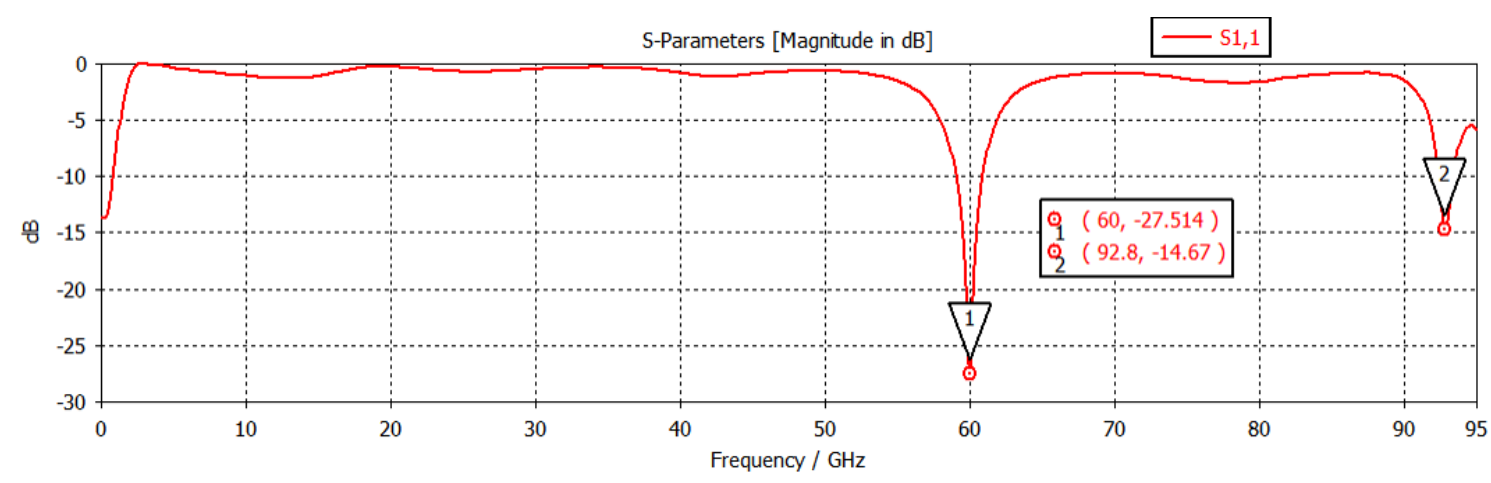

(a)

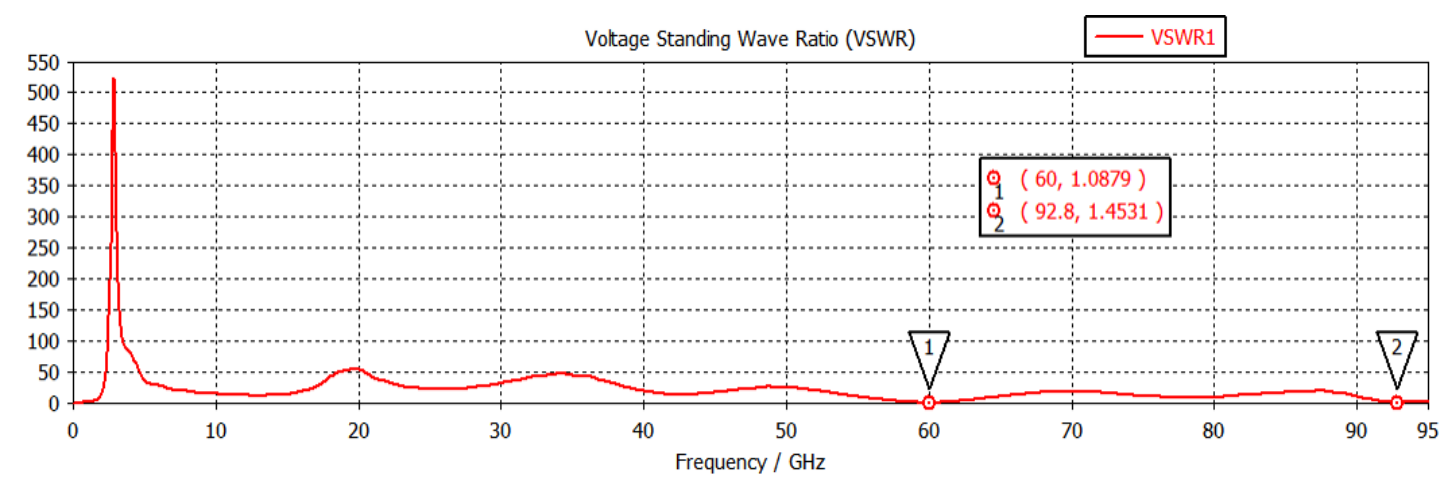

(b)

Figure 11. Dual-band of a 4patches $(1 \times 4)$ array antenna (a) return loss and (b) VSWR of d

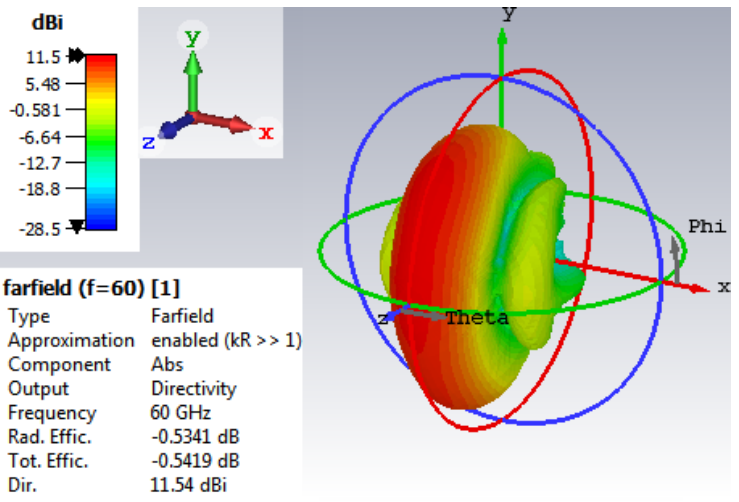

(a)

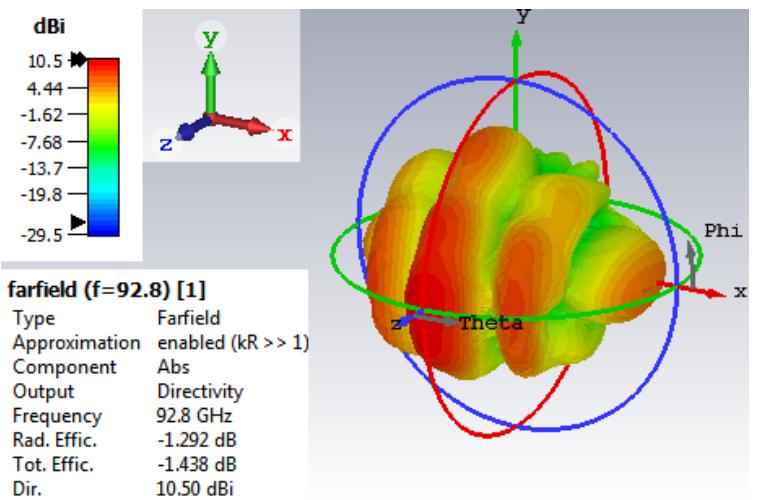

(b)

Figure 12. Directivity of $1 \times 4$ array at (a) $60 \mathrm{GHz}$ and (b) $92.8 \mathrm{GHz}$

\subsection{Comparison result of three design antenna implementation with other works}

The comparison between the results of three arrays in this research and other results of other researches is shown in Table 7. The results of this research can be summarized as: firstly, the size of the patch $(1.57 \mathrm{~mm} \times 2$ $\mathrm{mm}$ ) is the smallest RMSPA antenna that works on millimeter waves. Secondly, the three designs RMSPA antenna works with the dual bandwidth. Third, the performance for the three designs gives higher efficiency than the other work. Finally, the performance results for the directivity and power gain show that the best design is the 4 patches $(1 \times 4)$ compared with the 1 patch $(1 \times 1)$ and 2 patches $(1 \times 2)$. 


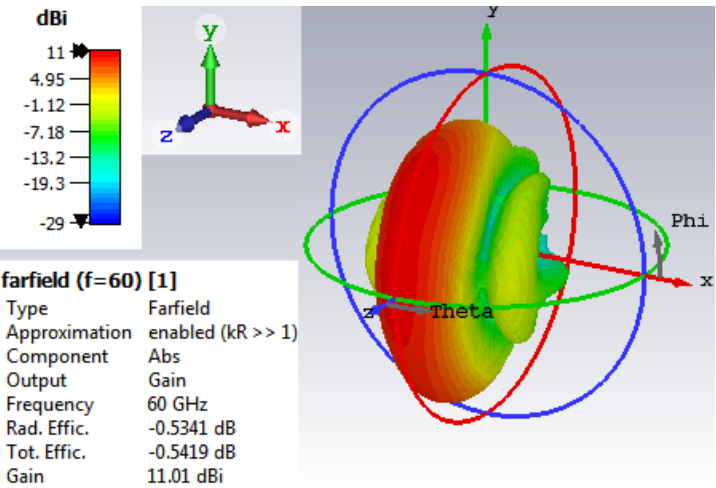

(a)

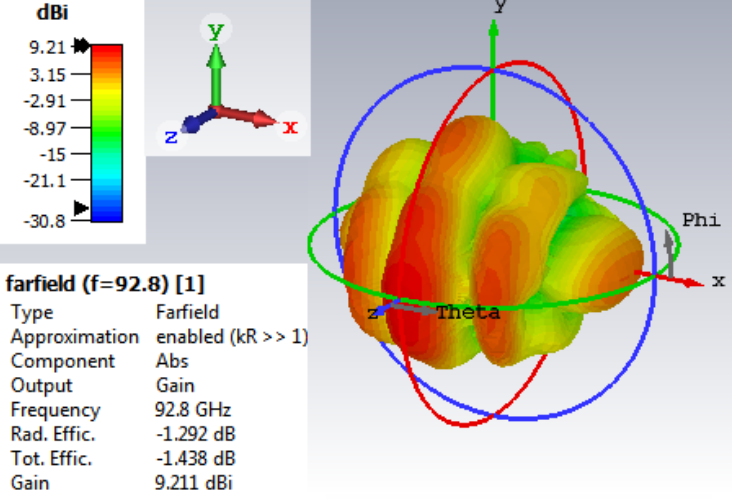

(b)

Figure 13. Gain of $1 \times 4$ array at (a) $60 \mathrm{GHz}$ and (b) $92.8 \mathrm{GHz}$

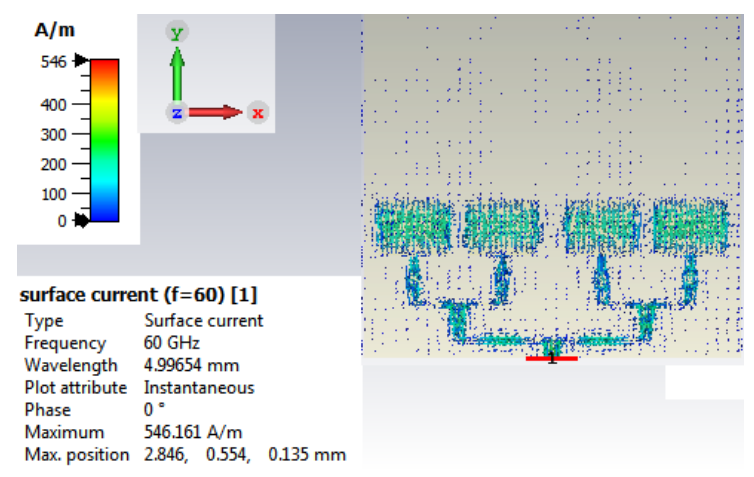

(a)

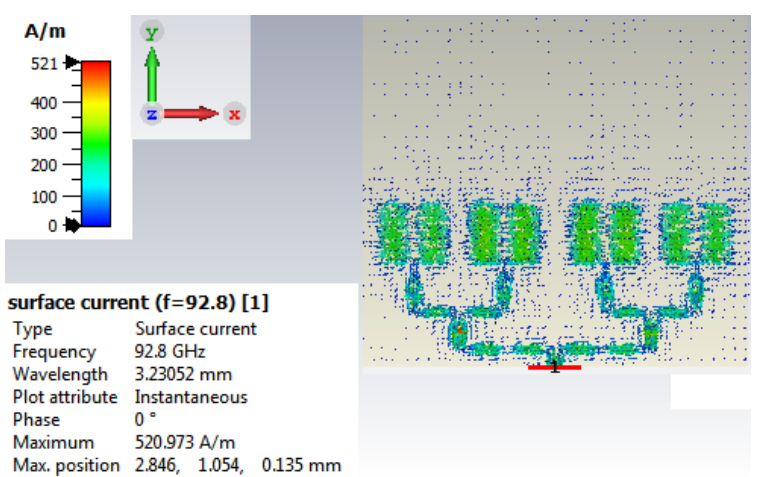

(b)

Figure 14. Current surface of $1 \times 4$ array at (a) $60 \mathrm{GHz}$ and (b) $92.8 \mathrm{GHz}$

Table 7. A comparison between other published and this our work

\begin{tabular}{|c|c|c|c|c|c|c|c|c|}
\hline & [Ref] & Size & $\begin{array}{l}\text { Resonance } \\
\text { frequency }\end{array}$ & $\begin{array}{c}\text { Return } \\
\text { loss }(\mathrm{dB})\end{array}$ & VSWR & Bandwidth & $\begin{array}{c}\text { Directivity } \\
(\mathrm{dBi})\end{array}$ & $\begin{array}{l}\text { Gain } \\
(\mathrm{dBi})\end{array}$ \\
\hline \multirow{8}{*}{$\begin{array}{c}1 \times 1 \\
\text { element } \\
\text { array } \\
\text { RMSPA }\end{array}$} & {$[20]$} & $2 \mathrm{~mm} \times 2 \mathrm{~mm}$ & $38 \mathrm{GHz}$ & -15.5 & 1.3 & $1.94 \mathrm{GHz}$ & 7.2 & 6.9 \\
\hline & & & $54 \mathrm{GHz}$ & -12 & 1.64 & $2 \mathrm{GHz}$ & 8.2 & 7.4 \\
\hline & {$[21]$} & $1.62 \mathrm{~mm} \times 2 \mathrm{~mm}$ & $60 \mathrm{GHz}$ & -22 & 1.173 & $1.375 \mathrm{GHz}$ & Not & 7.27 \\
\hline & [22] & $9.31 \mathrm{~mm} \times 11.86 \mathrm{~mm}$ & $10.6 \mathrm{GHz}$ & -14.33 & 1.47 & $\begin{array}{l}\text { Not } \\
\text { reported }\end{array}$ & $\begin{array}{c}\text { reported } \\
8.89\end{array}$ & 8.53 \\
\hline & This & $1.57 \mathrm{~mm} \times 2 \mathrm{~mm}$ & 60 & -14.338 & 1.475 & $1.2 \mathrm{GHz}$ & 7.493 & 6.673 \\
\hline & work & & 93.7 & -12.027 & 1.6682 & $1.1 \mathrm{GHz}$ & 7.376 & 6.833 \\
\hline & {$[21]$} & $1.62 \mathrm{~mm} \times 2 \mathrm{~mm}$ & $60 \mathrm{GHz}$ & -22.85 & 1.15 & $1.15 \mathrm{GHz}$ & $\begin{array}{l}\text { Not } \\
\text { reported }\end{array}$ & 10.7 \\
\hline & {$[22]$} & $9.31 \mathrm{~mm} \times 11.86 \mathrm{~mm}$ & $10.45 \mathrm{GHz}$ & -38.91 & $\begin{array}{c}\text { Not } \\
\text { reported }\end{array}$ & $\begin{array}{c}\text { Not } \\
\text { reported }\end{array}$ & 10.19 & 9.93 \\
\hline \multirow{3}{*}{$\begin{array}{c}1 \times 2 \\
\text { element } \\
\text { array }\end{array}$} & [23] & $27.62 \mathrm{~mm} \times 35.97 \mathrm{~mm}$ & $2.45 \mathrm{GHz}$ & -11.211 & 1.7588 & $29.3 \mathrm{MHz}$ & 9.633 & 9.225 \\
\hline & This & $1.57 \mathrm{~mm} \times 2 \mathrm{~mm}$ & $60 \mathrm{GHz}$ & -43.141 & 1.014 & $1.7 \mathrm{GHz}$ & 8.616 & 8.125 \\
\hline & work & & $94.4 \mathrm{GHz}$ & -19.669 & 1.2319 & $1.8 \mathrm{GHz}$ & 6.425 & 5.431 \\
\hline \multirow[t]{4}{*}{ RMSPA } & [20] & $2 \mathrm{~mm} \times 2 \mathrm{~mm}$ & $38 \mathrm{GHz}$ & -13.5 & 1.55 & $3.5 \mathrm{GHz}$ & 12.2 & 12.2 \\
\hline & & & $47.7 \mathrm{GHz}$ & -22.5 & 1.16 & $2.5 \mathrm{GHz}$ & 11.6 & 11.6 \\
\hline & & & $54 \mathrm{GHz}$ & -18 & 1.2 & $1.3 \mathrm{GHz}$ & 12.4 & 12.1 \\
\hline & {$[21]$} & $1.62 \mathrm{~mm} \times 2 \mathrm{~mm}$ & $60 \mathrm{GHz}$ & -32.7 & 1.047 & $1.3 \mathrm{GHz}$ & $\begin{array}{l}\text { Not } \\
\text { reported }\end{array}$ & 13.5 \\
\hline \multirow{4}{*}{$\begin{array}{l}1 \times 4 \\
\text { element } \\
\text { array } \\
\text { RMSPA }\end{array}$} & {$[22]$} & $9.31 \mathrm{~mm} \times 11.86 \mathrm{~mm}$ & $10.45 \mathrm{GHz}$ & -33.69 & 1.04 & $\begin{array}{c}\text { Not } \\
\text { reported }\end{array}$ & 13.18 & 12.85 \\
\hline & [23] & $27.62 \mathrm{~mm} \times 35.97 \mathrm{~mm}$ & $2.45 \mathrm{GHz}$ & -12.741 & 1.5995 & $35.5 \mathrm{MHz}$ & 11.79 & 11.73 \\
\hline & This & $1.57 \mathrm{~mm} \times 2 \mathrm{~mm}$ & $60 \mathrm{GHz}$ & -27.514 & 1.0879 & 1.7 & 11.54 & 11.01 \\
\hline & work & & $92.8 \mathrm{GHz}$ & -14.67 & 1.4531 & 0.9 & 10.50 & 9.211 \\
\hline
\end{tabular}




\section{CONCLUSION}

In this paper, three rectangular microstrip patch array antenna $((1 \times 1),(1 \times 2)$, and $(1 \times 4))$ are presented with simple and small structures. The proposed antenna is simulated by using electromagnetic simulation, computer software technology Microwave studio (CST) printed on Rogers RT5880 (lossy) substrate with dielectric constant 2.2, 0.0009 loss tangent, and thickness $0.1 \mathrm{~mm}$. The size of the patch for three designs of microstrip patch array antenna MSPAA is $(1.57 \mathrm{~mm} \times 2 \mathrm{~mm})$ and it works at dual-band. The good performance results in return loss, VSWR, directivity, and gain for the three designs necessary for many applications basically radar and communication. The three design results show that the best performance for the directivity and gain obtained by a 4 patchs $(1 \times 4)$ array.

\section{REFERENCES}

[1] D. Alvarez Outerelo, A. V. Alejos, M. Garcia Sanchez and M. V. Isasa, "Microstrip antenna for 5G broadband communications: Overview of design issues," 2015 IEEE International Symposium on Antennas and Propagation \& USNC/URSI National Radio Science Meeting, 2015, pp. 2443-2444, doi: 10.1109/APS.2015.7305610.

[2] X. Chen, K. Wu, L. Han and F. He, "Low-Cost High Gain Planar Antenna Array for 60-GHz Band Applications," in IEEE Transactions on Antennas and Propagation, vol. 58, no. 6, pp. 2126-2129, June 2010, doi: 10.1109/TAP.2010.2046861.

[3] W. Ahmad and W. T. Khan, "Small form factor dual band (28/38 GHz) PIFA antenna for 5G applications," 2017 IEEE MTT-S International Conference on Microwaves for Intelligent Mobility (ICMIM), 2017, pp. 21-24, doi: 10.1109/ICMIM.2017.7918846.

[4] T. Wu and T. Chang, "Interference Reduction by Millimeter Wave Technology for 5G-Based Green Communications," in IEEE Access, vol. 4, pp. 10228-10234, 2016, doi: 10.1109/ACCESS.2016.2602318.

[5] L. Wang, Y. Guo and W. Sheng, "Wideband High-Gain 60-GHz LTCC L-Probe Patch Antenna Array With a Soft Surface," in IEEE Transactions on Antennas and Propagation, vol. 61, no. 4, pp. 1802-1809, April 2013, doi: 10.1109/TAP.2012.2220331.

[6] H. Liu, P. Wen, S. Zhu, B. Ren, X. Guan and H. Yu, "Quad-Band CPW-Fed Monopole Antenna Based on Flexible Pentangle-Loop Radiator," in IEEE Antennas and Wireless Propagation Letters, vol. 14, pp. 1373-1376, 2015, doi: 10.1109/LAWP.2015.2406391.

[7] Y. Du and A. Zhao, "An Internal Quad-Band Printed Monopole Antenna for Oval-Shaped Mobile Terminals," IEEE Transactions on Magnetics, vol. 48, no. 2, pp. 683-686, Feb. 2012, doi: 10.1109/TMAG.2011.2174774.

[8] C. Chen, C. Sim and F. Chen, "A Novel Compact Quad-Band Narrow Strip-Loaded Printed Monopole Antenna," IEEE Antennas and Wireless Propagation Letters, vol. 8, pp. 974-976, 2009, doi: 10.1109/LAWP.2009.2030138.

[9] M. A. Abdalla and Z. Hu, "Design and analysis of a compact quad-band loaded monopole antenna with independent resonators," International Journal of Microwave and Wireless Technologies, vol. 10, no. 4, pp. 479-486, 2018, doi: 10.1017/S1759078717001453.

[10] A. Boukarkar, X. Q. Lin, Y. Jiang and Y. Q. Yu, "Miniaturized Single-Feed Multiband Patch Antennas," IEEE Transactions on Antennas and Propagation, vol. 65, no. 2, pp. 850-854, Feb. 2017, doi: 10.1109/TAP.2016.2632620.

[11] T. Dabas, B. K. Kanaujia, D. Gangwar, A. K. Gautam and K. Rambabu, "Design of multiband multipolarised single feed patch antenna," IET Microwaves, Antennas \& Propagation, vol. 12, no. 15, pp. 2372-2378, 2018, doi: 10.1049/iet-map.2018.5401.

[12] M. J. Alam, M. R. I. Faruque, M. M. Hasan and M. T. Islam, "Split quadrilateral miniaturised multiband microstrip patch antenna design for modern communication system," IET Microwaves, Antennas \& Propagation, vol. 11, no. 9, pp. 1317-1323, 2017, doi: 10.1049/iet-map.2016.0938.

[13] Y. F. Cao, S. W. Cheung and T. I. Yuk, "A Multiband Slot Antenna for GPS/WiMAX/WLAN Systems," IEEE Transactions on Antennas and Propagation, vol. 63, no. 3, pp. 952-958, March 2015, doi: 10.1109/TAP.2015.2389219.

[14] D. Mandal and S. S. Pattnaik, "Quad-band wearable slot antenna with Low SAR values for 1.8 GHz DCS, 2.4GHz WLAN, and 3.6/5.5GHz WiMAX Applications," Progress In Electromagnetics Research, vol. 81, pp. 163-182, 2018, doi: 10.2528/PIERB18052504.

[15] A. K. Gautam, L. Kumar, B. K. Kanaujia and K. Rambabu, "Design of Compact F-Shaped Slot Triple-Band Antenna for WLAN/WiMAX Applications," IEEE Transactions on Antennas and Propagation, vol. 64, no. 3, pp. 1101-1105, March 2016, doi: 10.1109/TAP.2015.2513099

[16] D. Fang, Y. Qian and R. Q. Hu, "Security for 5G Mobile Wireless Networks," in IEEE Access, vol. 6, pp. 4850-4874, 2018, doi: 10.1109/ACCESS.2017.2779146.

[17] A. Abdelaziz and E. K. I. Hamad, "Design of a compact high gain microstrip patch antenna for tri-band 5G wireless communication," Frequenz, 2019, vol. 73, no. 1-2, pp. 45-52, 2018, doi: 10.1515/freq-2018-0058.

[18] N. Al-Falahy and O. Y. K. Alani, "Design considerations of ultra dense 5G network in millimetre wave band," 2017 Ninth International Conference on Ubiquitous and Future Networks (ICUFN), 2017, pp. 141-146, doi: 10.1109/ICUFN.2017.7993764.

[19] C. A. Balanis, "Microstrip antennas." Antenna theory: analysis and design 3 pp. 811-882, 2005.

[20] D. Imran et al., "Millimeter wave microstrip patch antenna for 5G mobile communication," 2018 International Conference on Engineering and Emerging Technologies (ICEET), 2018, pp. 1-6, doi: 10.1109/ICEET1.2018.8338623.

[21] E. Dheyab and N. Qasem, "Design and Optimization of Rectangular Microstrip Patch Array Antenna Using Frequency Selective Surfaces for $60 \mathrm{GHz}$, International Journal of Applied Engineering Research, vol. 11, no. 7, pp. 4679-4687, 2016.

[22] H. Errifi, A. Baghdad, A. Badri and A. Sahel, "Design and Simulation of Microstrip Patch Array Antenna with High Directivity for 10 GHz Applications," International Symposium on Signal Image Video and Communications, November 2014.

[23] V. Prakasam, P. Sandeep and K. R. A. LaxmiKanth, "Rectangular Micro Strip Patch Array Antenna With Corporate Feed Network For Wireless Communication Applications," 2020 5th International Conference on Communication and Electronics Systems (ICCES), 2020, pp. 311-316, doi: 10.1109/ICCES48766.2020.9138028.

[24] C. Balanis, Antenna Theory Analysis And Design, Third Edition, A John Wiley \& Sons, Inc., Publication, 2005.

[25] D. M. Pozar, Microwave Engineering, Hoboken, NJ: John Wiley \& Sons, 2011. 


\section{BIOGRAPHIES OF AUTHORS}

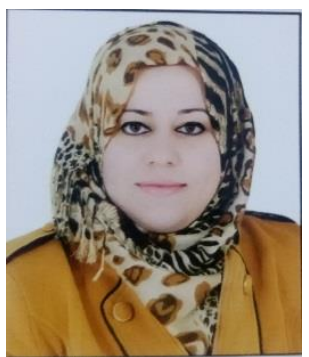

Shahad Dhari Sateaa (D) 8 SC P was born in Baghdad, Iraq in April of 1988. Received her B.Sc. degree in Electrical and Electronics Engineering from the University of Technology, Iraq in 2010, and an M.Sc. degree in Communication Engineering from the Department of Electrical Engineering, University of Technology, Iraq in 2013. Currently, she is Instructor at the computer Techniques Engineering department, Al-Esraa University College, Baghdad, Iraq. She can be contacted at email: shahad@esraa.edu.iq.

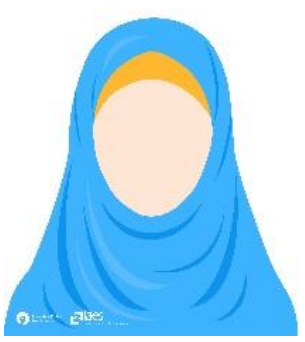

Maysam Sameer Hussein (DD IC P P she graduated from University of Baghdad with BSc. degree in Computer Engineering in 2011, and had her M.Sc. degree also in computer engineering from the same university in 2015. She is a faculty member at the Computer Engineering Techniques Department, Al-Esra'a University College, Baghdad, Iraq. She can be contacted at email: maysam@esraa.edu.iq

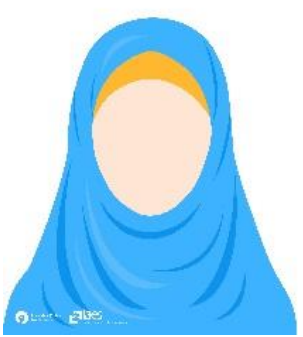

Zainab Ghazi Faisal (D) 8 SC P she graduated from University of Baghdad with BSc. degree in Computer Engineering in 2011, and had her M.Sc. degree also in computer engineering from the same university in 2014. She is a faculty member at the Computer Engineering Techniques Department, Al-Esra'a University College, Baghdad, Iraq. She can be contacted at email: zainab.ghazi@esraa.edu.iq.

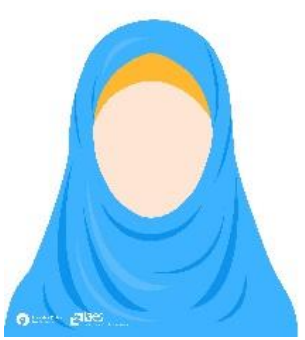

Amany Mohammad Abood (iD I8l SC P she graduated from Al-Nahreen University with BSc degree in computer science in 2005 and had her M.Sc. dgree also in computer science from the same university in 2009, she was a faculty member at the Computer Engineering Techniques Department, Dijla University College for four years and now is a faculty member at the Computer Engineering Techniques Department, Al-Esra'a University College, Baghdad, Iraq. She can be contacted at email: amany@esraa.edu.iq

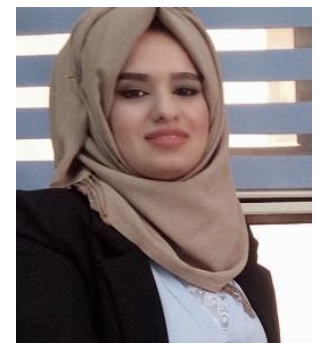

Huda Dhari Satea ID SC P P was born in Baghdad, Iraq in 1992. She received B.Sc. degree in Network engineering from Al-Nahrieen University, Baghdad, in 2014. And Higher Diploma in Information Technology/Website Technology from informatics Institute for Postgraduate Studies (IIPS), Baghdad, Iraq 2016. And M.Sc degree in Computer sciences from informatics Institute for Postgraduate Studies (IIPS), Baghdad, Iraq 2019. Her research interests in image processing and deep learning. She is working as Assistant Lecturer at ALEsraa University, Baghdad since 2014. She can be contacted at email: Huda@esraa.edu.iq. 